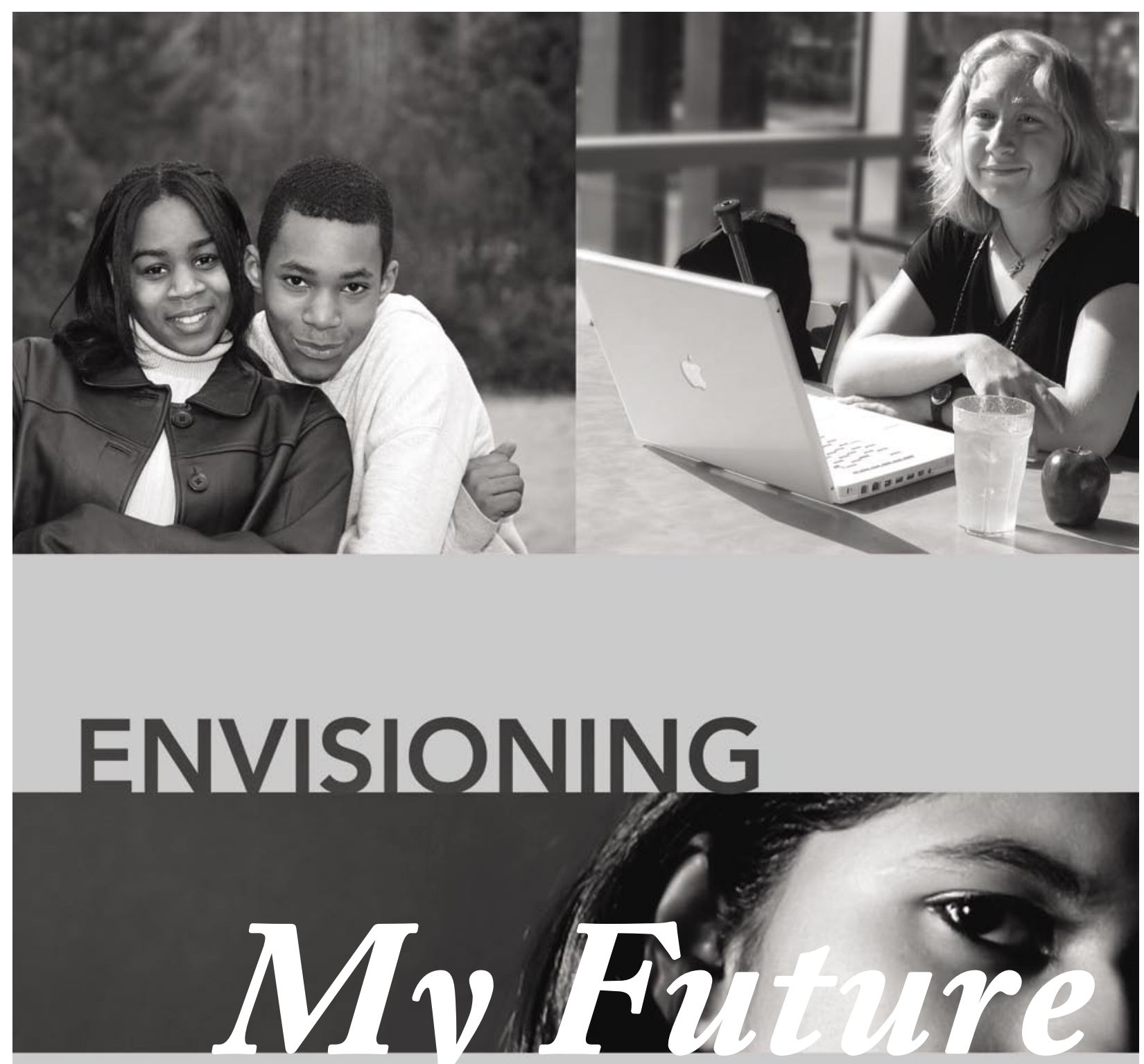

A YOUNG PERSON'S GUIDE TO HEALTH CARE TRANSITION CHILDREN'S MEDICAL SERVICES, FLORIDA DEPARTMENT OF HEALTH 


\section{ABOUT CMS}

The staff of Florida's Department of Health, Children's Medical Services (CMS) understands that transition to adulthood is an exciting time for teens and young adults. Transition may include changes in where you go to school, where you work, or where you live. Health care transition may include changing from pediatric care and services to adult care and services. Teens and young adults with special health care needs, and their families, need to know that health care transition takes a lot of thought and planning.

The staff at CMS wants to help with health care transition. One of our primary goals is to be sure that:

"Beginning at age 12, all teens and young adults with special bealth care needs who are enrolled in the CMS Network and their families receive the services needed to make transitions to all aspects of adult life, including adult bealth care, work, and independence."

This guide will help you and your family start thinking about health care transition and making a health care transition plan so that it will be a successful process. Health care transitions work best when they are planned. In order to plan, you and your family need to learn about new choices and new ways of getting health care services.

We hope that you and your family will read this guide and will begin to talk about this important part of your future. The staff at CMS looks forward to working with you to help make your health care transition as successful as possible.

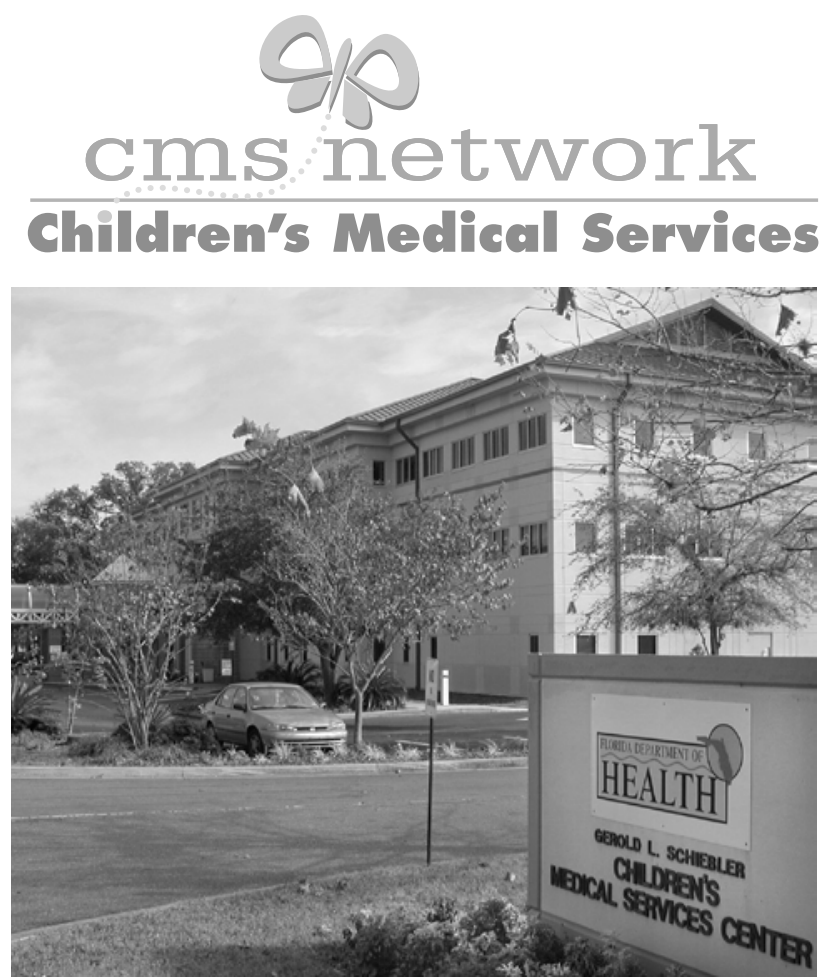




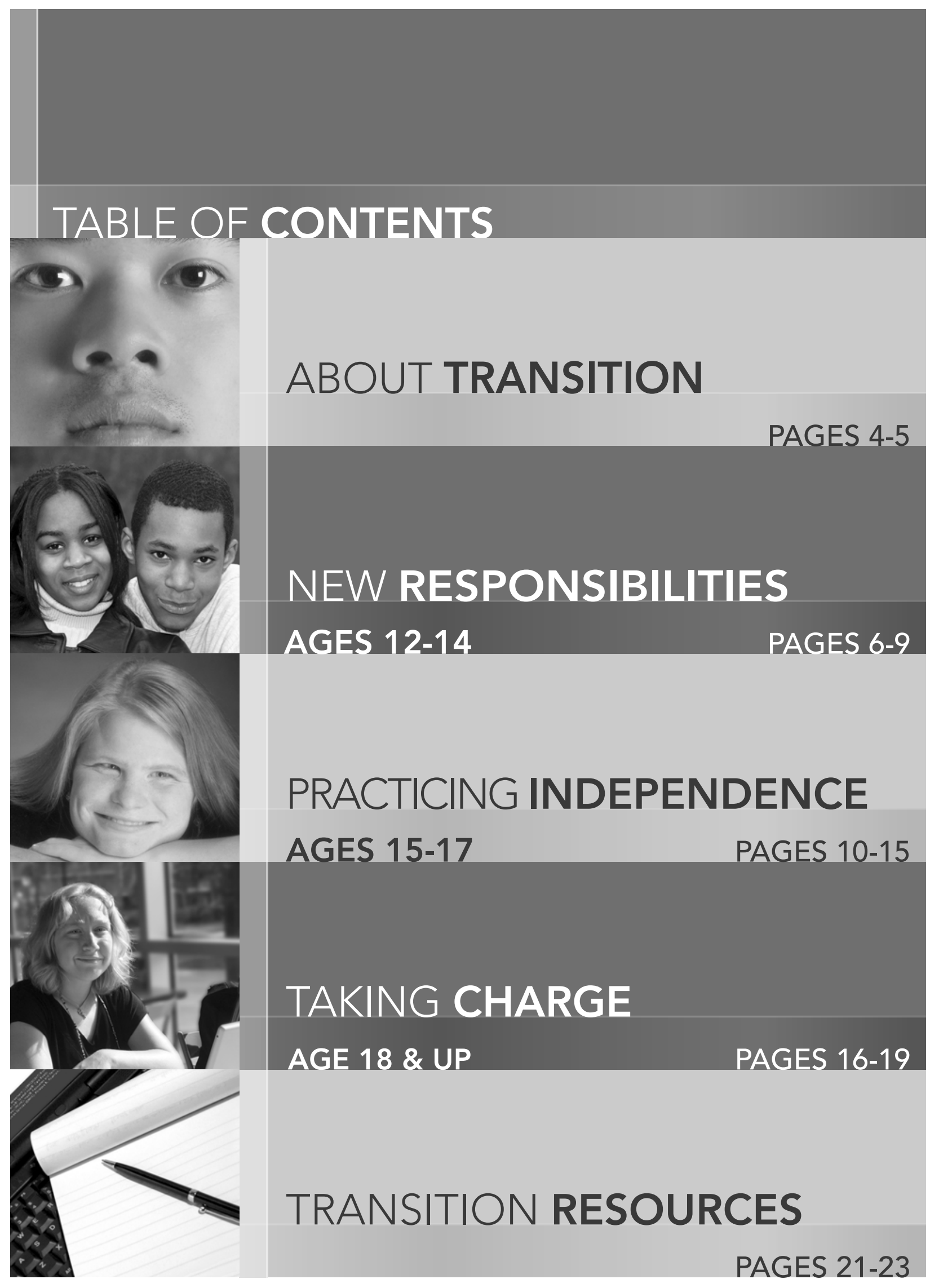




\section{ABOUT TRANSITION}

\section{"A smooth bealth care transition is very important to your bealth and well being. Now is the time to start planning."}

Growing up with a special health care need presents you with many challenges. Many people including your parents, doctors, CMS care coordinators, and therapists have helped to take care of you and have seen that you got the medical care that you need. However, now that you are getting older, you get to be more in charge of your health care. This will involve new responsibilities and privileges.

One important change that will happen over the next fewyears is saying good-bye to your pediatrician and going to see doctors who take care of adults instead. This process of leaving pediatrics and getting ready to go to adult-oriented medical providers is called health care transition. Health care transition is important because it supports the activities that you want to do in life such as living on your own, going to college, and having a job. In practical terms, health care transition not only means getting medical care from health care providers trained to treat adults, but also means becoming knowledgeable about your health condition, being responsible for carrying out your health tasks, and making good health care decisions. The purpose of this guide is to help you be successful in your transition from pediatric to adult health care.

Between now and when you become an adult, around the age of 21, it will be important for you to become responsible for managing your chronic illness or disability. This guide will give you some ideas about what you can do to help make your health care transition easier. It has three different sections, each highlighted with a different color. Each section is designed specifically for youth in a certain age range, and presents information about what you can do to become more independent in managing your health care.

\section{- The section for ages 12 to 14 (pages 6-9) focuses on "New Responsibilities."}

- The section for ages 15 to 17 (pages 10-15) looks at "Practicing Independence."

\section{- The section for young adults age 18 \& up (pages 16-19) focuses on “Taking Charge.”}

Each section contains some general information about health care transition activities and responsibilities for young people in that age group. There is also a checklist of things that you need to accomplish to help you see where you are on the road to a successful transition.

We have also included "Tips for Parents" in each section to give your parents some additional information and things they can do to help you be more independent and in charge. 


\section{ABOUT TRANSITION}

Even if you are 15 years or older, you should start this guide by reading the section for kids 1214. This is where you begin to learn about how you can get ready for health care transition. Read through the whole guide but don't fill out any of the checklists or do any of the activities. This will help you get an idea about what you need to know about health care when you are on your own. Then go back and do the activities in the section that is for young people your age. If you find that most of the activities in that section are too hard or involve things you are not ready for, look at the activities for a younger age group. Remember, we all have to start somewhere. Don't forget to share this guide with your parents since they can be a big help in preparing you for getting health care from adult-oriented doctors.

For a more comprehensive review of transition activities, ask your CMS care coordinator for a copy of the CMS Health Care Transition Workbook for your age group. The workbook will help you and your family think about your future and identify things that you are doing now to be independent in your health care. It will also help you figure out what you and your family need to do to assure that your transition from pediatric to adult-oriented health care and to other aspects of transition, goes as smoothly as possible.

Completing the workbook will help you, your family, your doctors, and Children's Medical Services know what you want your life to be like as an adult and what you and others need to do to help you reach your goals.

Health care transition makes a lot of sense when you understand how it supports the future goals you have for your life. Take a moment and think about your future by answering the questions under "Envisioning a Future."

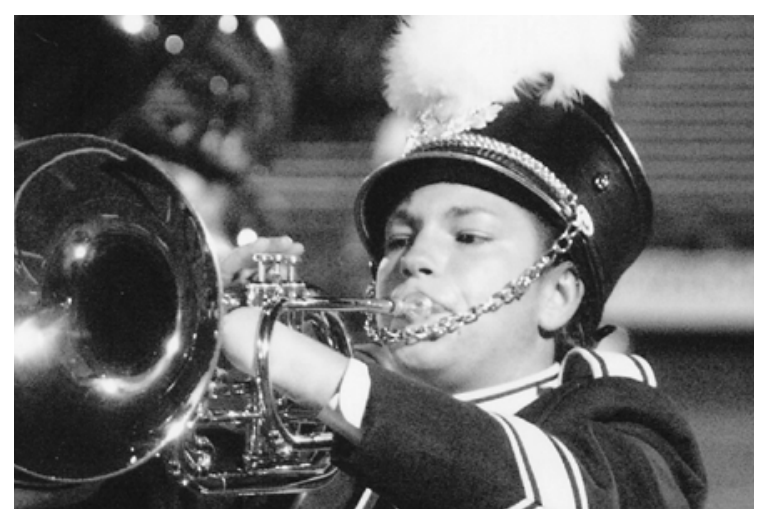

\section{Envisioning a Future}

"Envisioning a Future" means thinking about what you want to be and want to do when you get older. Health care transition is a process that will help you realize your dreams. To begin, answer the following questions:

- Will you finish high school?

- After high school, do you want to get vocational training or go to college?

- What type of job would you like to have?

- Do you want to be able to drive a car?

- Where do you want to live when you are an adult?

- Do you want a family of your own?

Now, think about how your health and medical independence will help you reach these goals. 


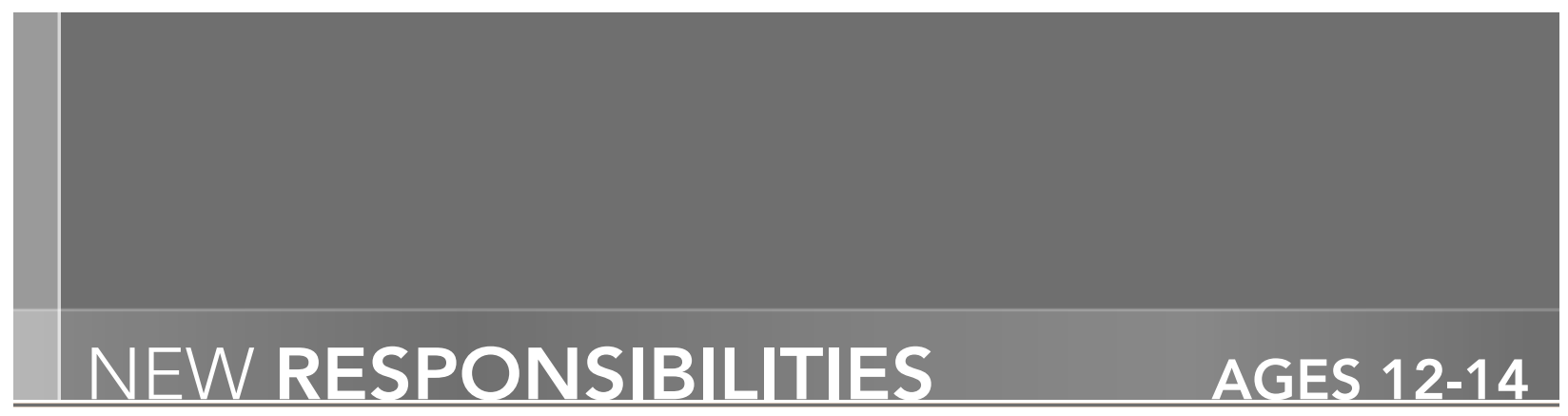

Elementary school is behind you and you are now in middle school. This move has meant many changes in your life including new freedoms and new responsibilities. One of the changes that you may have experienced in school is more responsibility for keeping track of assignments and homework. You are probably using a planner to write down and keep track of assignments that you have to do for school and other things you need to remember. This shift in responsibility is to help prepare you for high school, work, college, and future independence. Now is also a good time to take more responsibility for your health care.

You know that you need to be as healthy as you can in order to go to school, be with friends, and do the things you want to do. Up to this point, your parents have probably taken care of most, if not all, of your health-related activities such as reminders to take medications, working with doctors, or paying for the health care that has kept you healthy. In order for you to take over these responsibilities and have a job, go to college, and/or live independently when you are an adult (1821 years of age), it is necessary for you to learn about your health condition or disability. You need to begin to take responsibility for some of the activities that help to keep you healthy.

\section{So what can you do right now and over the next few years to become responsible for managing your health care?}

First, learn as much as you can about your health care needs. Do you know your diagnosis? Can you list your medications and when they are taken? Do you know what you have to do to stay healthy?

Second, try to do as much as you can. Do you carry out the tasks that keep you healthy? How much help and how many reminders do you need? Can you do these things independently? If there are activities or tasks that you cannot do, can you direct others to do them for you? There may be things that you will never be able to do all by yourself, but you can still learn how to tell someone else how to do these things for you. This is a great skill to have if you are away from home and need to ask someone for help, or if you are working with a new personal care assistant. This skill will also be helpful if you go away to college or want to live independently.

Third, actively participate in your health care. How much do you have to say during your doctor visits? Do you ask and answer questions during doctor visits or do you let your parents do that? Do you spend some time alone with your pediatrician? Do you agree to treatments and participate in health care decisions as an equal partner? 


\section{NEW RESPONSIBILITIES AGES 12-14}

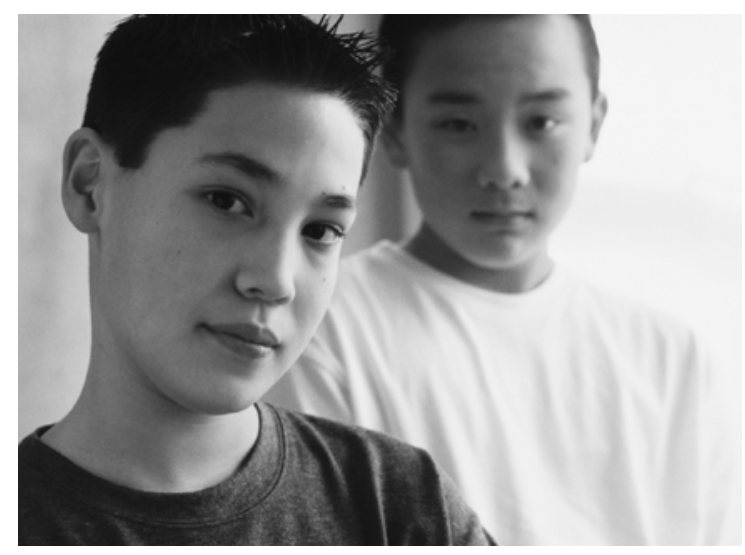

These questions and the ones in the checklist will help you determine the areas where you can be practicing responsibility. One of your goals over the next few years is to become an expert in your health condition and to become responsible for all of the activities that help to keep you healthy. This may seem like a lot to learn. However, if you start now and take one step at a time, you will be amazed at what you can accomplish over the next few years. By taking responsibility for managing your health care you will be working toward achieving the future goals you set out earlier in the "Envisioning a Future" section.

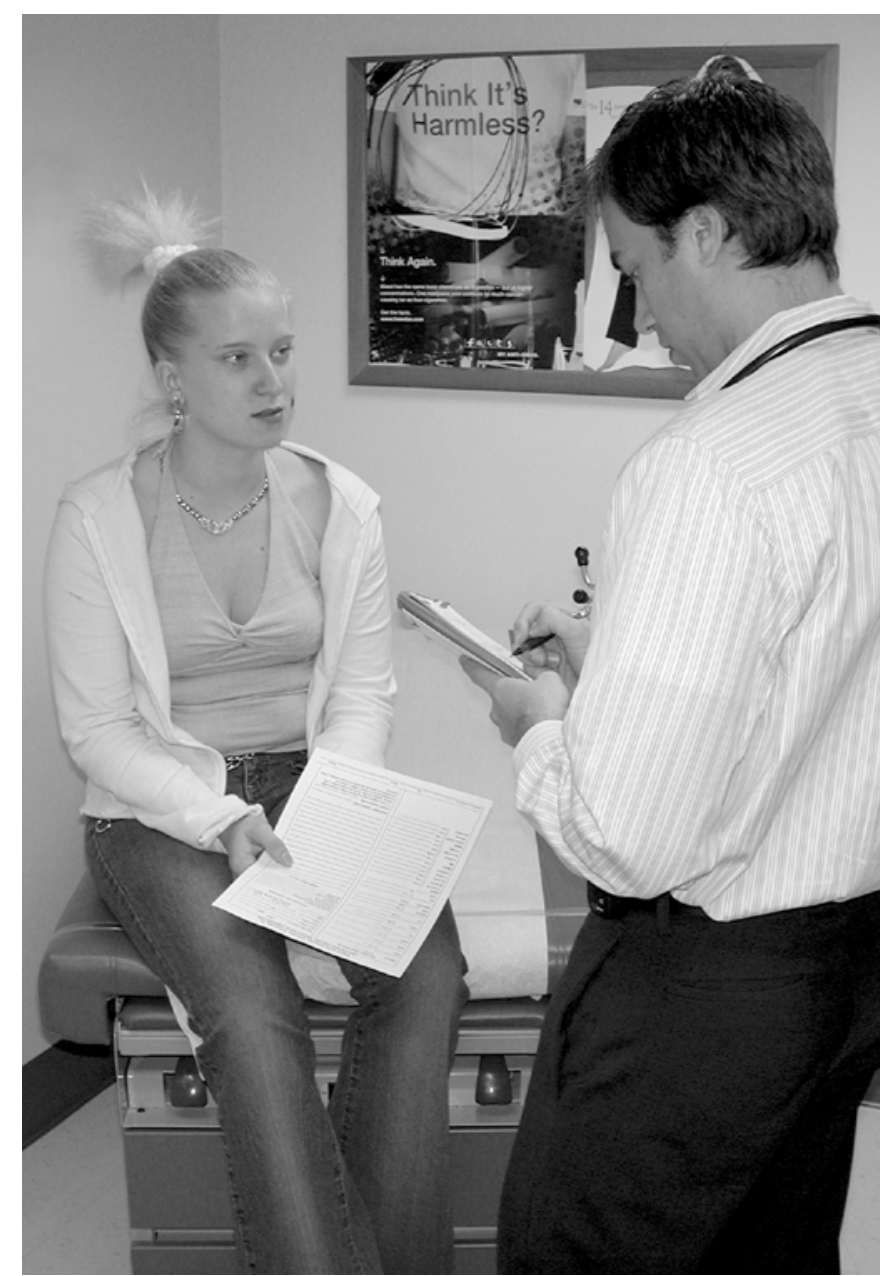

\section{"You need to begin to take responsibility for some of the activities that help to keep you bealthy."}




\section{Tips for Parents}

Young people with disabilities and chronic health care conditions are often at a disadvantage when it comes to getting a job, despite the fact that these young people want to work. Early work experiences,particularly part-time work, are very important. These experiences make a young person more attractive to future employers and help get young people to think about themselves as

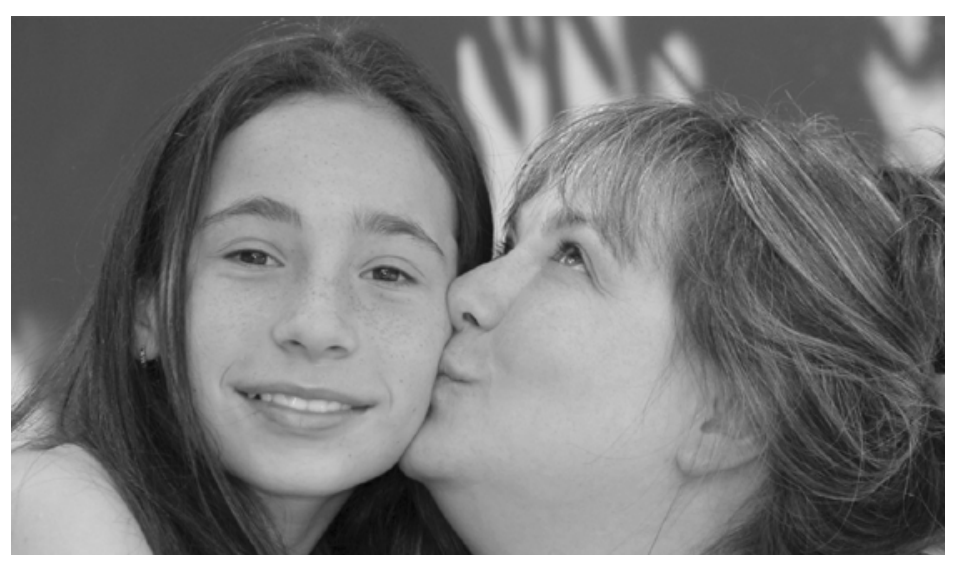
members of the workforce.

A survey of youth 12-18 years old conducted for the Social Security Administration found that these youth, even those with health conditions, reported being very interested in getting a job. Of all the age groups surveyed, young adults ages 13-14 with disabilities were most interested in career readiness programs. Seventh graders with special health needs actually had higher scores for positive attitude, interest, and competency toward work than those without disabilities. However, as the young people surveyed aged, scores decreased compared to healthy youth. This study tells us that pre-vocational programs and opportunities for part-time work should be targeted at those 13 and 14 years of age who are most interested in work.

\section{So how do you take advantage of this interest and channel it into focused work at school and ultimately productive employment?}

- Begin with chores around the house. The successful completion of chores are an excellent way to demonstrate personal independence and gain early work experience.

- Encourage and work with your child to participate in volunteer activities in the community. Your child might start by working for a disability advocacy group such as the Sickle Cell Disease Association, Spina Bifida Association, or the March of Dimes. Other opportunities for volunteering include the public library, animal shelters, church, and recreational programs.

- Explore and participate in pre-vocational and vocational support activities. Encourage your child to speak with vocational rehabilitation counselors and Independent Living Centers in your community. Check with the guidance counselor at your child's school for these and other resources.

- Encourage part-time work experiences. Use volunteer activities as work experience and as a spring board to paid employment.

- Discuss the relationship of good health, educational success, and future employment as a means of achieving personal goals. 


\section{Tips for Youth}

\section{What kind of a job do you want to have when you are an adult?}

Now is a good time to find out if your health condition or disability might limit the kind of work you can do when you become an adult. This will help you pick out the best courses in high school and help you decide what kind of training or additional education you might need. It's also a good time to find out if you are eligible for services from Florida's Department of Vocational Rehabilitation (Voc. Rehab.). Voc. Rehab. can start to work with people as young as 14 to help them figure out what they are good at, and what kind of job they would like to have. This state agency may be able to help you pay for special services and supports that you need while you are in high school to better prepare you for the world of work. Sometimes they can also help find the best vocational or technical school or college for you and pay for some of the costs of going to that school. Remember, it never hurts to ask.

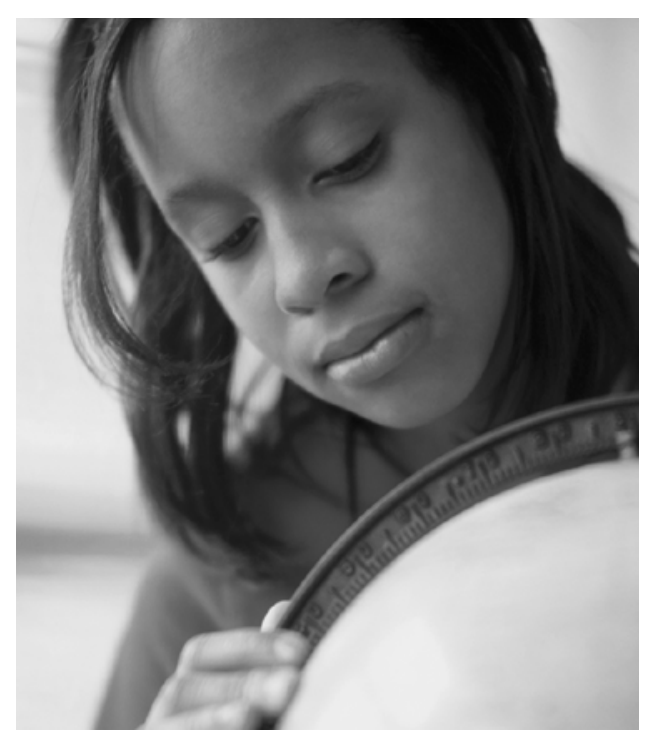

$\checkmark$ Transition Checklist

(Check the items that are true for you.)

I can describe how my disability or health condition affects my daily life.

I can name my medications (using their proper names), and the amount and times I take them.

I answer at least one question during a health care visit.

I have talked with my doctors or nurses about going to different doctors when I am an adult.

I manage my regular medical tasks at school.

I can call my primary care doctor's or specialist's office to make or change an appointment. 


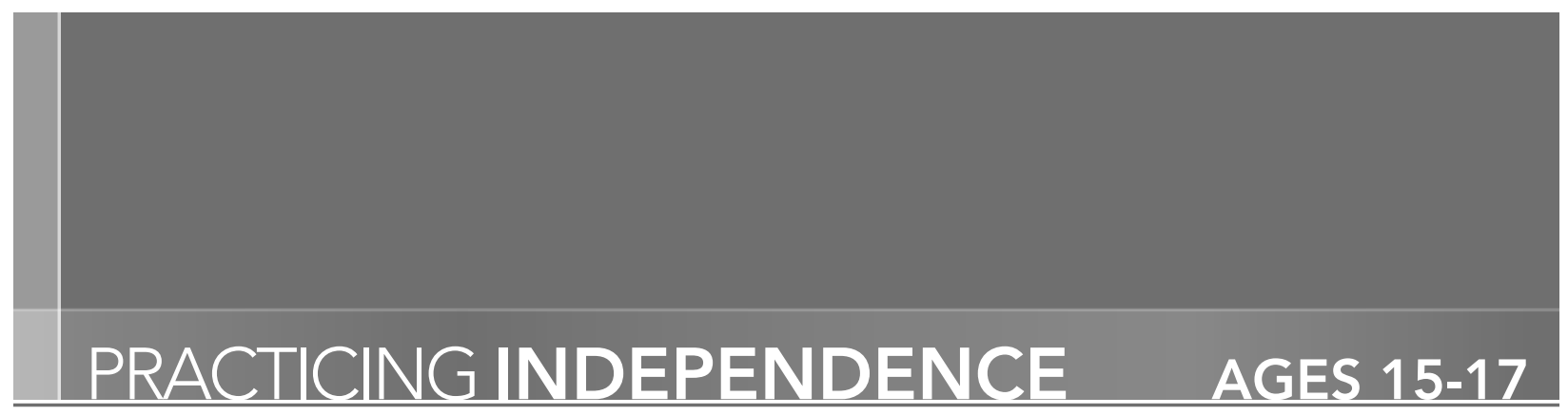

So, here you are in high school and you are probably thinking more about what you want to do with your friends this weekend than about the homework that is due tomorrow. Like other teens with a special health care need or disability, you might feel that adults treat you like a little kid and tell you what to do, check up to make sure you did it, or give you a hard time because you did not do it just the way they would. Other times you may feel like all the things you have to do and think about are just too much and you would like someone else to just take care of them for you. And sometimes you get so tired of having to take medicine, or go to therapy, or be in the hospital, and hearing from everybody about what you need to do to take care of yourself, that you just want to take a vacation from all the health care stuff.

Well, it can be work to manage a disability or special health care need. However, being able to carry out your health care activities provides you with a good opportunity to someday live independently, attend college, and have a job. But just like with other young people, successful independence doesn't just happen. You need to learn, develop, and practice the skills that support independence. It also feels good when adults really do listen to you, when your doctor understands what's most important to you, and when you get to have a life and not just an illness.

There are a lot of areas where you can practice being independent but we only have room to talk briefly about three: spending time alone with your doctor, keeping a medical journal, and preparing to transition to adult-oriented providers. We end this section with a brief discussion of the new legal rights that come to you when you turn 18 years old.

Now that you are in high school it is important to spend some time alone with your doctors and other health care providers. This means that you are going to have to practice giving the doctors the information they need about how you have been feeling, asking questions when you need more information, and talking about, and agreeing to follow, treatments. Up to this point, your parents have probably been asking and answering most of the questions during doctor visits and deciding what treatment they thought was best.

Talk with your parents about your interest in practicing independence during medical visits. Let them know that you would like to be more involved in your medical appointments, answer the doctor's questions, and help make health decisions. Ask them for help if you need it. You might also ask your parents to help you practice what you might say and develop some questions to ask. 
Another way to practice and prepare for independence during medical visits is to keep a medical journal. You or some of your friends may already be keeping a journal that records your experiences, thoughts, and feelings. A medical journal is a good place to keep track of experiences you have, which are related to your health care needs. You can also note questions for the doctor or other health providers and keep track of daily medical activities like routine procedures or taking medications. Next time the doctor asks you when or how often or what happened, you can use your journal and look it up. Remember to take

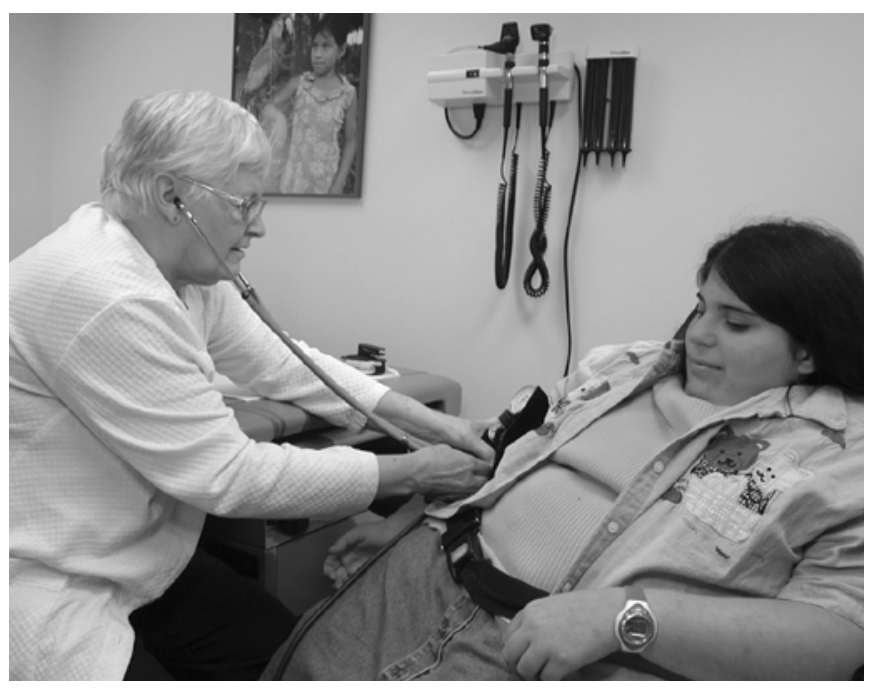
the journal with you to the doctor. To learn more about keeping a medical journal, check out the links in the "Transition Resources" section toward the end of this guide.

By beginning to talk to health care providers and being knowledgeable about your health needs, you are better prepared to talk for yourself if you have a medical emergency when you are out with friends. Your ability to give important medical information in an emergency will give you more personal freedom like attending a summer camp or traveling with a sports team.

Now is also the time to ask your doctor if she/he stops seeing patients when they get to be a certain age. The same is true if you get care from a children's hospital. It's a good idea to know if the hospital you usually go to has an upper age limit. Many children's hospitals and pediatric floors in general hospitals have a policy that limits admissions to individuals below a certain age. It is always better to know what the facts are, so that you have time to plan ahead.

Once you know when your doctors will transfer you, talk with them and your family about the things you need to think about when selecting new adult-oriented primary and specialty care doctors. It might be better for you to go to a doctor who is in a small practice so you are able to see the same doctor every time. That way you and the doctor really get to know each other. Or it might be better to go to a larger practice where there are a lot of doctors, but they see a lot of other people who have the same health condition as you do and are experts.

Sometimes it is hard to find adult doctors who know about taking care of adults whose health problem started during childhood. So it is important to give yourself at least a year to look for a doctor to take care of you when you are an adult. Regardless of what doctor you choose, your adult doctor will probably expect to see just you and will want you to be prepared to answer questions and to make decisions about treatments and tests by yourself. Now is the time to practice doing these things during your medical visits while your parents are able to give you a hint or two. 


\section{PRACTICING INDEPENDENCE AGES 15-17}

\section{Tips for Young Adults}

When you turn 18 years old, you legally become an adult.

If you are 16 or 17 , now is the time to find out how your legal rights and responsibilities will change when you turn 18. Did you know that in Florida when you turn 18, you are legally an

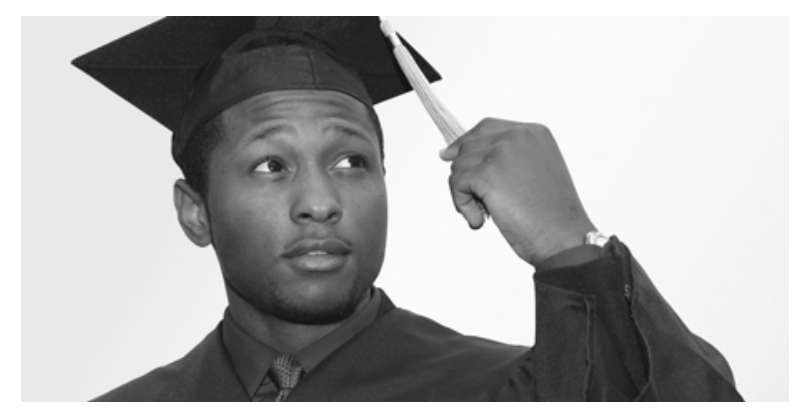
adult and you can do anything any adult can do (except purchase alcohol)? As an adult, you have the right to have most medical and other information about you kept private from everybody, including your parents. You will also be the one who signs the medical consent forms. By signing these forms, you say that you understand what the doctors have told you and agree to certain tests, surgeries or procedures. Doctors can't talk with any other people about you, even your parents, unless they have your written permission to do so. If there is an emergency, doctors cannot share information with your parents or talk with them about what things you do and do not want to be done to your body (remember - when you turn 18, you are in charge) unless you have signed a "release of information" form ahead of time. In the "Transition Resources" section, there are links to web sites and other things to read about your new legal rights, your rights to privacy, and how to give permission to doctors to share information with your parents or with other people who you want involved in decisions about your care.

On page 15 there is a checklist that gives you some other things you can practice in order to be more independent. After you do the checklist, talk with your parents and doctors, and decide together what things are most important for you to practice doing on your own now.

\section{College Bound}

Health care transition is all about providing you with a healthy foundation on which to build your life goals. Going away to college or vocational training may be part of your plans for the future. If so, there are some things you can do to help make this transition to a new school and to new health care providers easier. Even if you are not going away to school, some of the tips can be helpful.

The transition to a college away from home takes some planning. Once on campus, your parents will not be there to help you with your care, make decisions, or solve problems. Therefore, it will be important to plan ahead and make sure you are as prepared as possible to be in charge of your health care.

Let's begin with some questions. What medical care do you need when you are away from home? Do you need physical assistance? Will you be using personal assistants to help you complete activities of daily living? Once you have determined what you need, you will have to check to see if these services are available at the colleges you are considering. All colleges have an Office for Students with Disabilities. Contacting this office is a good place to begin. Some colleges have worked hard to make their campus and educational programs very accessible. These colleges tend to have more comprehensive programs to help you adjust and succeed in college life. 
If you think that you will need special housing arrangements at college because of your health care needs, be sure to talk with your school's Office for Students with Disabilities. Many colleges have only a few dorm rooms that are specially equipped for students with special needs and these spaces fill up quickly. Let your school know about your needs as soon as possible, so that they can make your living arrangements as comfortable, accessible, and safe as possible.

In addition to making arrangements with your new school, you will also need to make arrangements for getting the health care you will need while you are away at college. Even if you are still receiving services from pediatric providers, you should not expect to get care from pediatric providers in your new location. To make arrangements for health care, begin by talking to the college or student health center to find out if they can or cannot meet your medical needs.

The student health center at many colleges and universities can provide care to students with a cold or sprained ankle, but do not have the staff or expertise to meet the needs of students with special

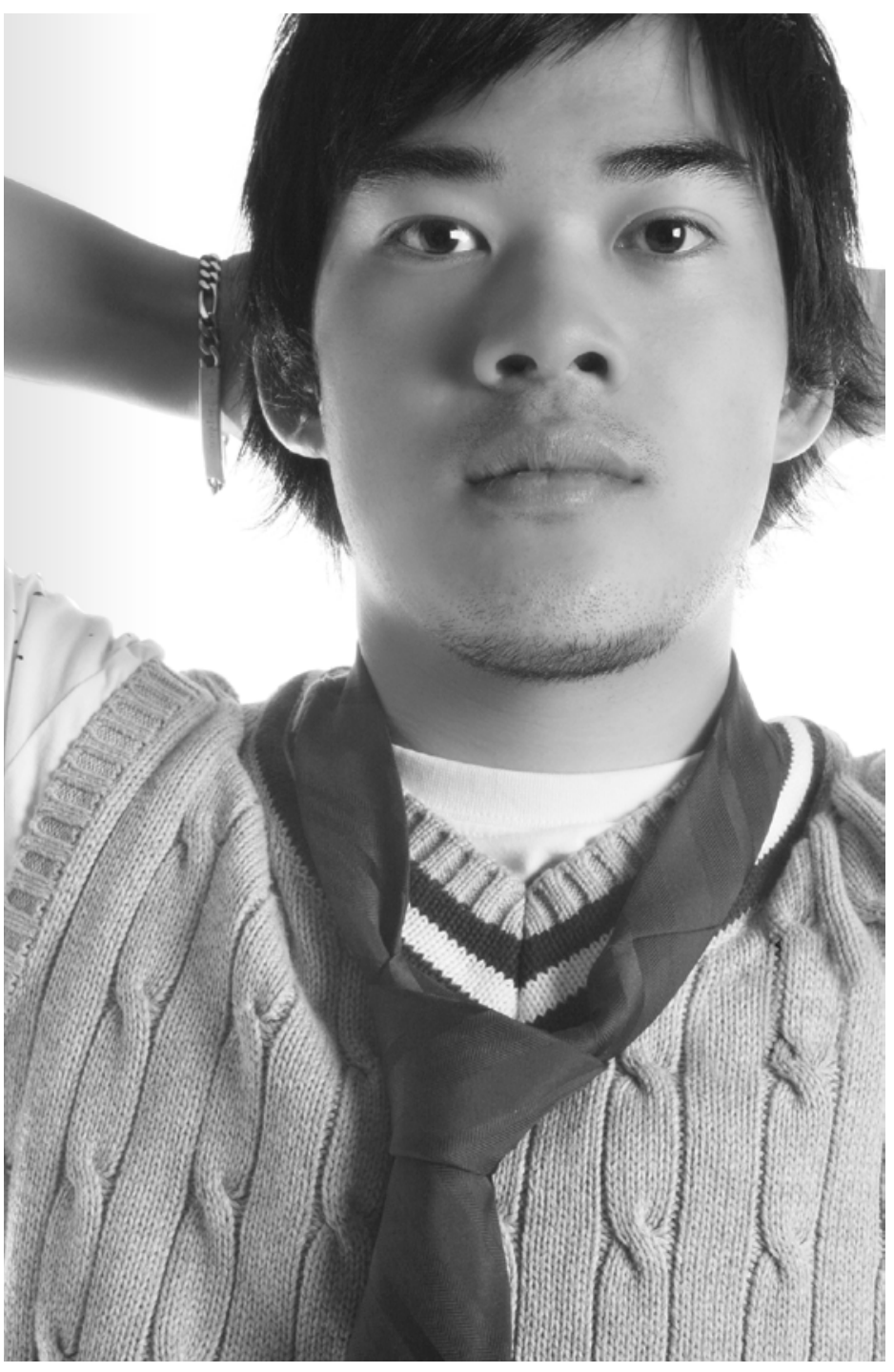
health care needs or disabilities. Although the student health center might be willing to work with your home town doctors, you might be happier if you find a primary care provider who practices close to your college.

If the student health center is unable to meet all your health needs, you will need to find a local health care provider. Finding a new provider may take some effort on your part so you will want to start this process as early as possible. After you have found a new provider, arrange an introductory meeting so you can discuss your care, ask questions, and learn about the doctor's treatment approach. You may want to ask your current provider and new provider to talk directly with each other. Once this has been arranged, have your medical records sent to your new provider. 
The next step is is to prepare for medical emergencies and arrange for other medical supports that you generally use such as medications, medical equipment, and medical supplies. Develop a plan for medical emergencies. Write it down and share it with the people that need to know about this plan such as the Resident Advisor on your dormitory floor, your roommate, or others who might help you in an emergency.

If you take medications, know where you can get your prescriptions filled. If you use medical equipment or a wheel chair, find out how the equipment can be repaired or replaced. If you have dietary restrictions, discuss these with the Office for Students with Disabilities and the food service on campus.

It's also a good idea to let your academic advisor at college know about your special health needs or disability and how this might affect your ability to take a full course load. When you are in high school, your guidance counselor and other staff are supposed to take the first steps to get you the accommodations you need. When you are in college, it is up to you to let the Office for Students with Disabilities and other school officials know about your needs. Don't wait until you get behind to let them know you need help and support. Under some circumstances, students with chronic health conditions or disabilities are allowed to take a reduced course load, but still be considered "full-time students" by the health insurance company. It's much better to take 2 courses and get Bs than to try to take 5 courses and get Cs and Ds.

This overview can't tell you everything you need to know about transitioning your health care services to a college setting, but it does show how you will need to use the transition skills you have been working on. Now, work hard in high school to get the grades needed for the college of your choice so you can put your transition skills to work.

\section{Tips for Parents}

\section{When your Child Turns 18: Privacy and Guardianship}

Did you know that after your child turns 18 that you (parents) no longer have automatic access to your child's personal health information? Once your child turns 18 years old, health care providers are required by law to respect the right to confidentiality of personal health information. Health care providers cannot provide this information to parents unless they have written permission to do so. This situation presents both opportunities and challenges.

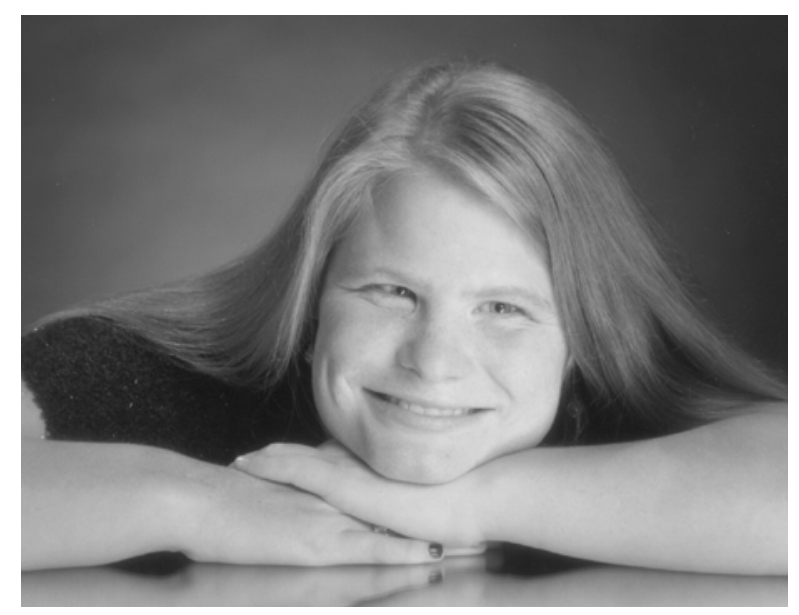

The right to privacy of personal health information can help to prompt you and your child to discuss the changes in responsibility that will occur on their 18th birthday. This discussion can make clear the limitations that parents face and how a young adult at age 18 becomes the responsible person for medical decision-making. 


\section{PRACTICING INDEPENDENCE AGES 15-17}

For some young adults whose ability to make informed decisions is diminished, informal supports may be sufficient. This can involve a network of family and friends providing informal support and guidance. It is important to recognize these informal networks must still operate within privacy laws. Steps for developing and maintaining such an informal network include signing "release of information" forms so that family members will have access to medical information if the young adult so chooses.

Other young adults whose ability to make informed decisions is more limited, may need the formal supports that are provided through guardianship. Guardianship is a legal process that takes time and money and involves submitting a formal application to the county probate court. Guardianship is a legal, rather than a medical determination, and involves the courts formally declaring that an individual is "incompetent" and unable to make certain decisions for themselves, and appoints another adult or adults to make such decisions. In many cases, the appointed guardian is a parent, sibling, or other family member. However, a trusted friend or staff of a public guardianship agency can also serve in this role.

The issue of guardianship and other legal supports is a complicated one. Some advocates believe that guardianship denies an adult with a disability their civil rights. Others believe that guardianship, or other legalsupports,are sometimes necessary to assure the safety and well-being of some adults with disabilities. Parents and the professionals involved in a young person's care want young adults to be independent and self-sufficient, but at the same time, want them to be safe.

$\checkmark$ Transition Checklist

(Check the items that are true for you.)

I keep a personal health notebook or medical journal.

I reorder my medications when my supply is low and call my doctor when I need a new prescription.

I answer many of the questions during a health care visit.

I spend most of the time alone with the doctor(s) during health care visits.

I tell my doctors I understand and agree with the medicines and treatments they suggest.

I know if my doctors do not take care of patients who are older than a certain age (for example, 21).

I regularly do chores at home.

I can tell someone the difference between a primary care doctor and a specialist. 


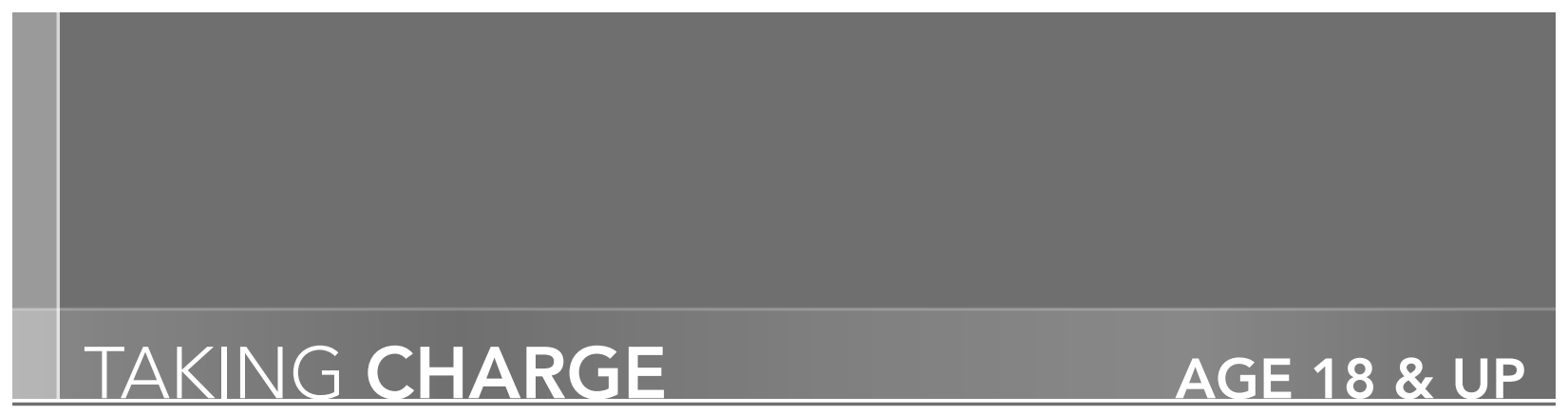

You may not have felt any different, but when you turned 18 you legally became an adult. As an adult, you gained the right to vote, sign contracts, give consent for medical procedures, and control who has access to your medical information. With the rights of adulthood also came new responsibilities. This guide will help you learn about how these responsibilities can affect your ability to get health care.

The time you have been preparing for is now here. You have become more knowledgeable about your health care condition, you are more independent in carrying out or directing others to carry out the health care tasks that keep you healthy, and you know when you will leave the pediatric doctors that you have been seeing. Completing the transition process will involve a few more steps: transferring to adult-oriented providers, developing a good relationship with these new providers, establishing your new leadership role in managing your health care, and ensuring that you have ongoing health insurance coverage.

You might have asked for a referral from your pediatrician, talked with friends, or received assistance from a local support group to find an adult-oriented doctor who will be responsible for providing your care. As part of the process of finding the right adult-oriented doctor for you, meet with the doctor when you are in good health to discuss your understanding of your special health care need and any treatment preferences. Adult-oriented medical procedures are frequently different from treatment practices in pediatrics. It is important to discuss these differences and express your preferences, and to also consider the suggestions of your new doctors. This give and take around medical decisions is part of building a new working relationship. You and your parents trusted your pediatric provider because of the many years you worked together. Now you have to build new trusting relationships. Remember this will take some time.

A very important part of developing a new relationship is saying good-bye to the doctors, nurses, and therapists who you worked with while growing up. It can be hard to leave the people and places you have known for a long time. You will probably miss seeing these individuals who have worked closely with you and your family. As part of saying good-bye, ask if it is okay to keep in touch after you are no longer a patient. Most pediatric providers enjoy hearing about how their patients are doing after they "graduate" from their practice. You can send an email, letter or drop in for a personal visit. However, it is important to remember that you do have a new doctor and your old doctors can no longer give you medical care or advice.

Another big change is that you are now responsible for making decisions about your care. This can be an important and sometimes difficult change for your parents. After all, helping to take care of you has been one of their major concerns for a long time. Encourage your parents to think of the change in decision-making as a promotion. They have been promoted from managers to consultants. For your part, remember that your parents have a lot of experience with your health and they can be a great source of information and support as you take charge of making your own health care decisions. 
Paying for health care can be very challenging. At this point you may still be covered by your parents' health insurance or some combination of public or private plans. Most likely this will change over the next few years. Keeping health insurance is very important over the next few years. If your insurance coverage depends on you being in college, then you need to be successful in school. Not only for the short-term, but also for the long-term. This will help you get a job that has health insurance benefits. If you qualify for a public health insurance plan such as Medicaid, it is important to be aware of the rules and requirements that need to be met in order to continue receiving it. You do not want to find yourself sick with no way to pay for the care you need. Learn more about continuing health insurance coverage by reading the "Tips for Young Adults."

\section{Tips for Young Adults}

\section{Getting, Keeping, and Using Health Insurance}

As you probably have heard again and again from your parents, health care is very expensive. When you are 21, you will be too old to qualify for CMS. So, you need to figure out how you can get and keep health insurance when you are an adult, so that you can continue to get the health care you need.

Because health insurance is a very complex issue, and eligibility requirements and benefits can change, especially in public programs such as Medicaid, this section includes only general information about paying medical bills. However, a list of sources with more detailed and current information about insurance in Florida is included in the "Transition Resources" section of the guide.

\section{Medicaid}

Medicaid is a public health insurance program for people with low incomes. When you turn 21, you might continue to qualify for Medicaid, even though you are too old for CMS. However, you need to be aware of the following facts:

- If you qualify, financially, for Medicaid at age 18 you might not quality for Medicaid when you turn 19 , even if you earn the same amount, or have the same amount of money in the bank.

- Medicaid pays for a lot of health care services for individuals who are under age 21, but pays for many fewer services for adults (individuals who are 21 or older). For example, if you have Medicaid and are under age 21 and your parents need help to take care of your medical needs, Medicaid can pay for many hours of in-home nursing care. However, when you turn 21, Medicaid might pay for much less care.

- When you turn 21, you might have to enroll in a Medicaid managed care program, and be assigned to a new primary care doctor who is not familiar with you and your medical needs.

- Even if you were not financially eligible for Medicaid in the past, you may be eligible when you turn 19 because you can be considered as a "family of one", for the purposes of determining financial eligibility, even if you continue to live with your parents.

Discuss with your CMS Nurse Care Coordinator how your Medicaid coverage might change when you turn 19. 


\section{Medicaid and SSI}

In Florida, if you get Supplemental Security Income (SSI) benefits, you are automatically eligible for Medicaid coverage. The financial eligibility criteria for SSI are higher than those for Medicaid in Florida, so you can earn more and still get Medicaid if you qualify for SSI. In addition, when you turn 18, the SSI Program considers you to be independent and your parents income and assets don't count when determining your financial eligibility for SSI.

Having SSI may also allow a student to take a reduced course load at college if needed. Some students with extensive health care issues do better managing a course load of 2-3 courses rather than being a full-time student, which most health care insurance requires. This can make a big difference in academic success for students with disabilities.

It can take a long time for the government to decide if you quality for SSI. Talk to your CMS Care Coordinator approximately six months before your 18th birthday so you can get the ball rolling.

\section{Family Coverage}

Some employers offer family health insurance coverage, so you may be covered under the health insurance that one of your parents has through their place of work. While coverage usually ends when a child turns 19, some programs might allow you to be covered until you are older $(24,25$, 26) if you are a full or part-time student, or if you are disabled and your parents help to support you. More information about family coverage is included in the "Tips for Families."

\section{Health Coverage through Work}

Some employers offer health insurance to their workers, but most require that employees pay for part of the cost of the insurance. When starting out, it may seem like a lot of money is deducted from your pay check to pay for insurance. However, it is a lot less expensive than having to pay the full costs of a visit to the ER or a day in the hospital all by yourself. Picking the right insurance plan can be a hard decision. Look in the "Transition Resources" section for information to find out how to choose the best plan to meet your needs.

\section{Health Coverage while Away at School}

When you are in college, you may want to go to doctors near your college during the school year and go to doctors in your home town during the summer. Be sure that your insurance company will allow you to switch back and forth between doctors during different times of the year. Some insurance companies will only allow you to see a primary care provider who is in your home town. Be sure to talk to your insurance company before you go away to school. 


\section{Tips for Families}

\section{Helping Young Adults with Health Insurance Issues}

The upper age limit for coverage of dependent children under employer-based health plans varies. While coverage typically ends when a child turns 19 , some policies allow young adults to continue to be covered if they are a full or part-time student, are disabled (according to the Social Security Administration's definition), or if parents provide more than half of their adult child's support. Read your family health insurance policy carefully to understand your options. You must start planning early, especially if your child needs to get an evaluation through the Social Security Administration. To be sure that coverage continues, you should contact your insurance company or employer five or six months before your child turns 19, to tell them that you have a dependent adult child and you want coverage for that child to continue.

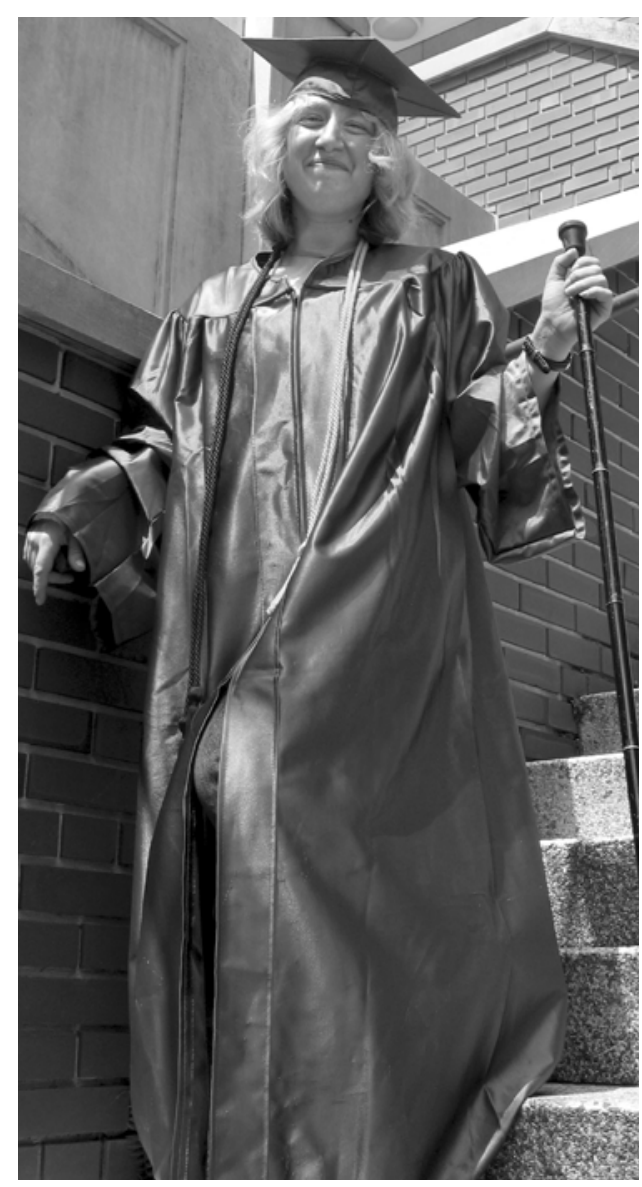

\section{$\checkmark$ Transition Checklist}

I can tell someone the effects that getting older may have on my disability or health condition.

I can tell someone about medications that I should not take because they might interact with the medications I take.

I am alone with the doctor(s) or choose who is with me during health care visits.

I answer all the questions during a health care visit.

I have identified adult doctors and facilities that I will go to when I leave my current doctors and facilities.

I manage all of my regular medical tasks outside the home (school, work).

I can tell someone what new legal rights and responsibilities I gained when I turned 18 years old (sign medical consent forms, make medical decisions by myself).

I can tell someone how long I can be covered under my parent's health insurance plan and what I need to do to maintain coverage (such as be a fulltime student). 


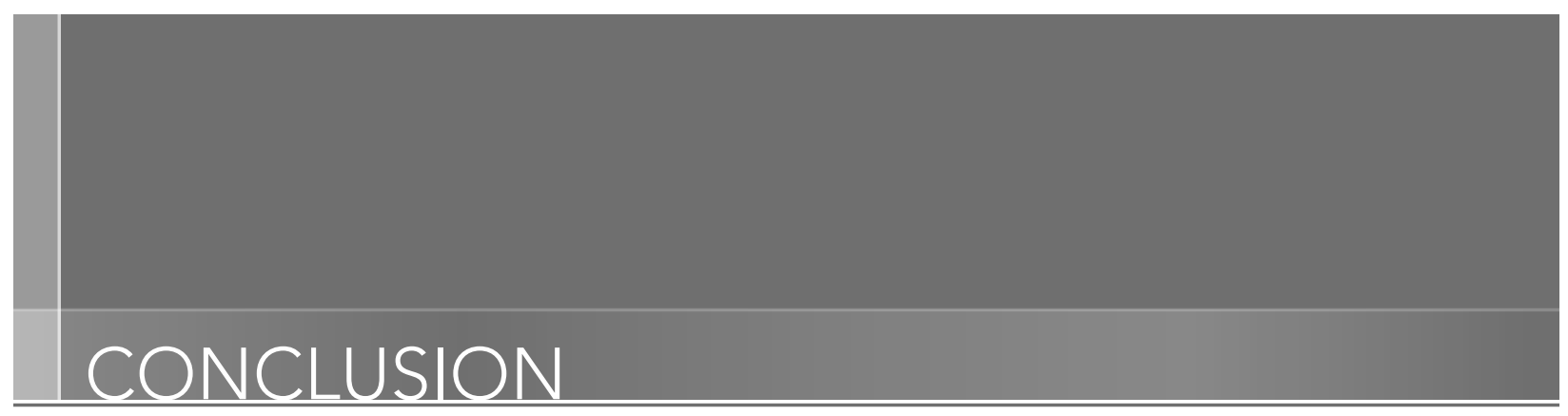

Growing up with a special health care need can present you with many challenges. However, young people with chronic health conditions and disabilities who were able to meet these challenges and reach their goal of being independent and having a good job, say that they had to do several things to be successful. They had to:

\section{- take responsibility for themselves}

\section{- manage their own health care}

\section{- be as physically fit and healthy as possible}

By reading this guide to health care transition, completing the checklists, and looking at some of the additional resources, you and your family have taken an important first step on the road to a successful health care transition.

You have learned that getting ready to go to adult-oriented health care providers is important because it helps you to do the things you want to do in life, such as living on your own, going to college, and having a job.

You have learned that health care transition takes time, planning, and practice. It involves becoming knowledgeable about your health condition, being responsible for doing health care tasks for yourself, and making health care decisions. It is about taking on new responsibilities, practicing independence and finally, taking charge. It is important to remember that this guide is only an introduction and does not cover all aspects of health care transition. Health care transition is also an individual process and there is no one right way to transition.

Well, you've done it. You are now an adult and are learning how to exercise your new privileges and responsibilities. As you become more independent, think about all the efforts your family and pediatric health care providers have invested in you. It is now your job to take good care of your body and your health by making good decisions in all aspects of your life. This will let you not only envision your future but make it actually happen.

Be sure to look at the following "Transition Resources." Contact the ones that provide information that may be helpful to you.

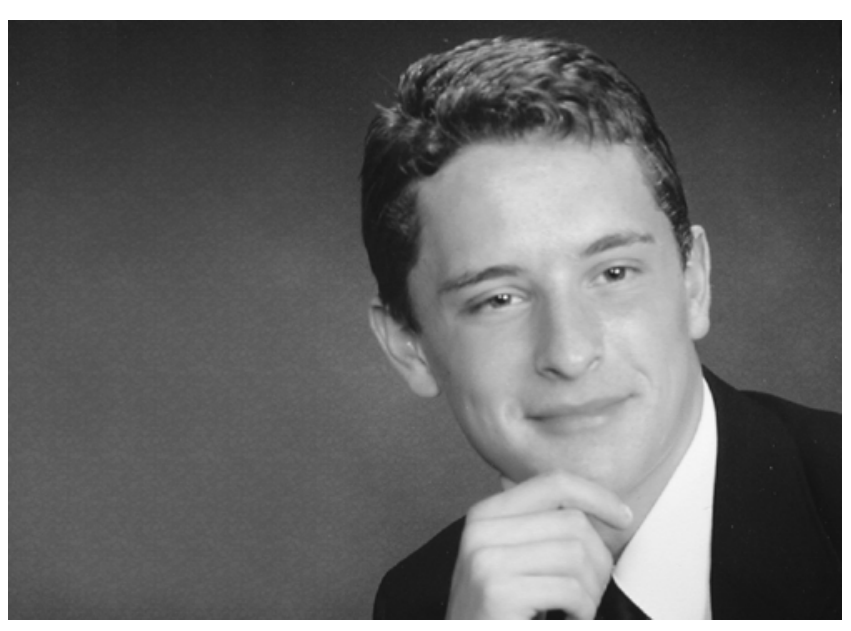




\section{TRANSITION RESOURCES}

\section{Florida Resources}

\section{Advocacy Center for}

Persons with Disabilities

Client Assistance Program (CAP)

Web Site: www.advocacycenter.org/programs/cap

CAP assists anyone with a disability who is interested in applying for and receiving services from rehabilitation programs, projects, or facilities funded under the Rehabilitation Act.

Agency for Health Care Administration (AHCA)

Phone: Toll Free: 1-888-419-3456

Web Site: www.fdhc.state.fl.us

Information, questions and answers, office locations, and eligibility guidelines for Medicaid. Health care advance directive forms can be downloaded from the web site.

\section{Children's Medical Services (CMS)}

Department of Health

Phone: (850) 245-4200 (Tallahassee)

Web Site: www.cms-kids.com

CMS Network Area Offices are located throughout

Florida. For transition information see:

www.cms-kids.com/CMSNTransition.htm

Clearinghouse on

Disability Information

Web Site: www.abilityforum.com

Florida listing of information and resources for persons with disabilities or long-term illnesses.

\section{Department of Education}

Bureau of Exceptional Education and Student Services Phone: (850) 245-0475 (Tallahassee)

Web Site: www.firn.edu/doe/commhome

Administers programs for students with disabilities and for gifted students. Coordinates student services to strengthen the quality and variety of services available to students with special needs.

Developmental Disabilities Program Agency for Persons with Disabilities Phone: (850) 488-4257 (Tallahassee)

Web Site: www.myflorida.com

(Search for Agency for Persons with Disabilities) Assists persons with developmental disabilities and their families to identify and secure supports and services.

\section{Division of Vocational Rehabilitation}

Web Site: www.rehabworks.org

A statewide employment resource for businesses and people with disabilities to enable people with disabilities to obtain and keep employment.

Family Network on Disabilities of Florida/ The Tiles Project

Phone: Toll Free: 1-800-580-7801

Web Site: www.fndfl.org/tiles.htm

A statewide family support and disability resource network. The Tiles Project addresses transition, independent living, and employment issues. 


\section{TRANSITION RESOURCES}

\section{Florida Resources Cont.}

Florida Alliance for Assistive Services and

Technology (FAAST)

Phone: (850) 487-3278 (Tallahassee);

1-888-788-9216 (Toll Free)

Web Site: www.faast.org

FAAST works with consumers, family members, caregivers, providers and agencies to ensure that individuals continue to benefit from assisted technology as they move between home, school, work and community.

Florida Institute for Family Involvement Phone: Toll Free: 1-877-926-3514

Web Site: www.fifionline.org

Provides information, resources, and advocacy for children with special health care needs and their families.

\section{Florida Statewide Guardianship Office}

Web Site: http://elderaffairs.state.fl.us

Information for professionals and families about guardianship including potential sources of legal services.

\section{FYI Transition}

Web Site: www.fyitransition.org

A Florida transition web Site for youth with disabilities and their families that is being developed by The Transition Center at the University of Florida.

\section{Health Care Surrogate Designation in Florida}

Web Site: www.fdhc.state.fl.us

Forms and instructions regarding designating a health care surrogate.
Health Care Transition Initiative at the Institute for Child Health Policy

Phone: (352) 265-7220

Web Site: http://hctransitions.ichp.ufl.edu

Source for transition listservs, videos, training materials, and other resources for health care transition.

\section{Legal Guide for New Adults in Florida} Web Site: www.flabar.org

(Click Consumer Services, then Consumer Pamphlets) This pamphlet, which was developed by the Florida Bar, is designed to help youth understand the legal rights and responsibilities they assume when they turn 18 and become adults from a legal perspective.

\section{National/Federal Resources}

\section{Disabilitylnfo.gov}

Web Site: www.disability.gov

This federal web site links to information of interest to people with disabilities, their families, employers, service providers, and other community members. Topics include employment, education, housing, transportation, health, income support, technology, community life, and civil rights.

\section{GovBenefits.gov}

Phone: Toll Free: 1-800-333-4636

Web Site: www.govbenefits.gov

Confidential online screening tools to help individuals find out which government programs and benefits they may be eligible to receive. 


\section{TRANSITION RESOURCES}

\section{National/Federal Resources Cont.}

Healthy and Ready to Work

National Center

Phone: (202) 884-8650

Web Site: www.hrtw.org

Information, tools, resources, and links to many transition-related web sites.

National Center in Secondary Education \& Transition

Web Site: www.ncset.org

Web site includes resources related to education, training, independent living, and work for youth with disabilities.

\section{Social Security}

Phone Toll Free: 1-800-772-1213 or

1-800-325-0778 (TTY)

Web Site: www.ssa.gov/disability

Information about eligibility and applications for SSI and SSDI.

The Arc

Phone: (301) 565-3842

Web Site: www.thearc.org

Web site includes guardianship information.

\section{Other Resources}

\section{Girls Health}

Web Site: www.4girls.gov

Promotes healthy, positive behaviors in girls between the ages of 10 and 16. Gives girls reliable, useful information on the health issues they will face as they become young women and tips on handling relationships with family and friends at school and at home.

\section{Build Your Own Care Notebook}

Web Site:

www.medicalhomeinfo.org/tools/care_notebook.html

Provides access to several different care notebooks.

Choosing \& Using a Health Plan

Web Site: http://www.ahrq.gov/consumer/hlthpln1.htm A booklet on health insurance.

\section{CMS Health Care Transition Workbooks}

Web Site:

http://hctransitions.ichp.ufl.edu/resources.html

Workbooks for youth, young adults, and their families.

\section{CSHCN Emergency Planning Form}

Web Site:

http://hctransitions.ichp.ufl.edu/resources.html

Form for documenting information that can be used by professionals to care for a child with special health care needs in case of an emergency.

\section{Evaluating Managed Care Plans for $\mathrm{CSHCN}$}

Web Site: http://policyweb.ichp.ufl.edu/ichp/purchaser/ A tool for assessing how well a managed care plan will meet the needs of CSHCN.

Youthhood.org

Web Site: www.youthhood.org

Provides transition planning for youth with or without disabilities, teachers, community service providers, parents, guardians, and anyone else interested in transition from high school to adult life. 


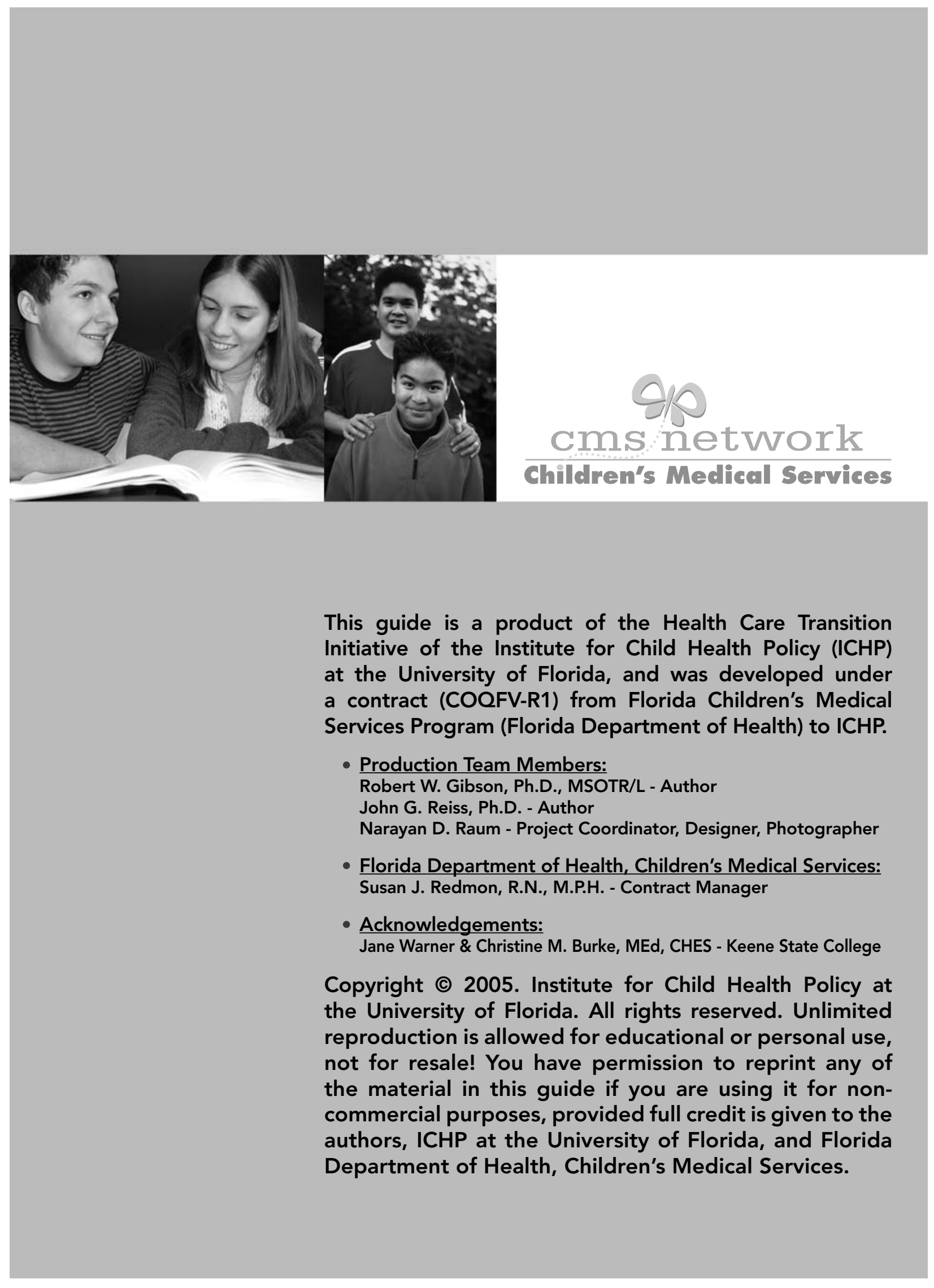

